\title{
A Holistic Approach to Safety and Security at Schools in South Africa
}

\author{
Mgadla Isaac Xaba
}

North-West University: Vaal Triangle Campus; OPTENTIA/School of Educational Sciences; Vanderbijlpark Email:Ike.Xaba@nwu.ac.za

\section{Doi:10.5901/mjss.2014.v5n20p1580}

\section{Abstract}

This article reviews literature on school safety and security and proposes a holistic approach to safety and security at schools in South Africa. This is based on the fact that ensuring a safe and secure school has become an important part of schooling in South Africa. This is due to the many reported incidents of violence at schools, in classrooms and in immediate school communities. Based on the view of the school environment as comprising physical and psychosocial spaces, I argue that the safety and security of the physical environment is a critical enabling factor for the safety of the whole school and also lays the basis for the safety of the psychosocial environment. Therefore ensuring school safety and security requires a holistic approach that encompasses a thorough grounding in knowledge about the school environment and the basics of school safety. Based on these arguments, I make the point that school facilities maintenance and surveillance of the school environment are critical aspects of a holistic approach to safety and security of a school. With this in mind, I present an approach that can be helpful in making schools safe and secure.

Keywords: school safety; safety measures; natural surveillance; access control; territoriality

\section{Introduction}

Schools generally are concerned with creating effective teaching and learning spaces for both teachers and learners. Sadly, school communities find themselves in situations where other concerns take up most of their energies with a result that the core business of schools although important, often becomes a secondary priority. In particular, schools are faced with matters of safety and security. Numerous incidents of violence and injuries are reported in the media. While these do not provide the causes of such incidents, empirical research evidence on school safety in South Africa does detail their causes. On this basis, numerous solutions are provided and combined with legislative provisions, beginning with the Constitution and further prescribed in subsequent national and provincial legislation such as the Schools Act and various amendments thereof. In fact, legislation seems to cover almost all aspects of safety and security of learning institutions. Among others aspects, relevant pieces of legislation address issues such as visitation to schools; regulations for safety measures at public schools; measures for emergencies and fire procedures including emergency evacuations, installation and maintenance of fire extinguishers and alarms as well as the conduct of fire drills; declaration of schools as drug and dangerous objects-free zones; directives relating to dangerous objects or illegal drugs in school premises; and random body searches and or randomly administering urine tests to learners who are reasonably suspected of using illegal drugs.

Despite these measures and best practices aimed at ensuring safety at schools, incidents resulting in injuries and sometimes death, continue and seem in fact to be on the increase. For instance, recent incidents include firstly, a case of a five year old learner who was killed allegedly when fellow learners pushed him in front of a heavy-duty lawnmower at a primary school in Soweto (Naik, 2014). Secondly, an eight year old girl died at hospital following excessive bleeding due to being kicked and beaten by three bullies at another primary school (City Press, 2014). Thirdly, a boy died after falling into a pit toilet at a primary school in the Limpopo Province (Moloto, 2014). Fourthly, a teacher at a secondary school was shown in a video that had gone 'viral' being pursued and assaulted by a learner, while his fellow learners seemed to be cheering him on (The Citizen, 2014a). Yet in another incident, a schoolboy shot and wounded a teacher at a high school in Sasolburg in the Free State (The Citizen, 2014b). In fact according to Mncube and Harber (2013, p. 40), commonly reported incidents at schools as reported by one principal include "stabbing with a pair of scissors, stabbing with a knife, stealing a teacher's cell phone, taking other learners stuff such as books and pens, using drugs, bullying, verbal abuse which lead to physical fighting and pointing fingers at teachers and promising to beat them".

These incidents indicate the vulnerability of both learners and staff at schools. Therefore schools seem to be beset or even under siege of violent and other safety-threating incidents. The question then is: why do these incidents proliferate despite legislative provisions aimed precisely at curbing them? 
It is important to note that safety threatening incidents appear to be two-fold - those that school communities can deal with through adherence to and implementation of best practices in safety and security measures as detailed in legislation and those over which they do not have control like crime in the community and incidents emanating from poverty and related socio-economic factors. It must also be noted that safety measures and legislative provisions aimed at curbing safety threats at schools are in themselves not a guarantee against such incidents, but a catalyst to the end safety and security. For this reason, human behaviour in the form of best practices in school safety and security is an essential element. This implies correct and positive attitudes to, and knowledge of school security, safety and commitment to the implementation of safety measures. However, it can be argued that the main shortcoming seems to be located in the implementation of measures to ensure that schools are safe and secure. Indeed research on school safety and security related matters in South Africa, while indicating gaps resultant from poor resources at schools, highlights the lack of implementation of basic safety and security measures. For instance, among other studies, the following studies present findings and/or recommendations regarding safety and security measures and their implementation at schools:

- In his study, Managing School Safety in the Primary School, Nhlapo (2006) found that there was poor implementation of safety measures at schools and recommended that schools should embark on proper strategic planning for safety and security, engage all stakeholders and advocate the outcomes of such safety planning so that all involved are knowledgeable about the contents of such plans.

- Xaba (2006), found in his study An Investigation into the Basic Safety and Security Status of Schools' Physical Environments, that while school environments displayed some measure of basic safety, there was lack of conscious efforts aimed at creating safe and secure environments and recommended that schools focus on the basic safety and security of their physical environments, inter alia, purposefully planned school-based maintenance, surveillance and collaboration with stakeholders, including outside agencies like law enforcement.

- Van Jaarsveld (2011) found in her study An Investigation of Safety and Security Measures at Secondary Schools in Tshwane, South Africa, that most security measures needed attention at schools and these included security guards (stationary fixed position), fire alarm systems, limited number of access entry points to school grounds/building entrances/exits, guards patrolling the premises/perimeter, doors secured with security gates, ID cards/badges for scholars, random drug testing at the school for scholars and adult supervision in halls. She also found that the majority of the scholars and educators were not familiar with the written security plans and most schools did not have the appropriate emergency plans in place at their schools.

- In their study, School Violence in South Africa: Results of the 2012 National School Violence Study, Burton and Leoschut (2013) recommend that the planning and implementation of school safety plans and strategies should be integrated into local development and safety plans, ensuring partnerships with other relevant local stakeholders, with clear lines of responsibilities and accountability defined and that making a real impact on school violence and achieving safe school environments is only likely to happen when school safety is integrated as a fundamental component of local safety strategies, and when the role and commitment of all stakeholders - beyond just schools - is recognised and secured in working towards local level community safety strategies.

- Maphalala and Mabunda (2014), in the study Gangsterism: Internal and External Factors Associated with School Violence in Selected Western Cape High Schools point out from their findings that "schools have policies and codes of conduct for learners in place to deter substance abuse and violent behaviour. Despite the existence of these policies, violence, physical and sexual abuse and gang activities are still the order of the day in Western Cape schools".

- Mncube and Madikizela-Madiya (2014), in their study, Gangsterism as a Cause of Violence in South African Schools: The Case of Six Provinces, recommend that schools that experience problems of violence need an active safety and security committee that monitors violence, recommends violence prevention measures and oversees its implementation.

It is therefore important to unlock the potential in processes aimed at ensuring that schools are secure and that safety practices are a basic consideration at schools. To this end, I seek to present an approach to school safety and security that focuses on:

- a thorough grounding in knowledge about the school environment safety and security;

- the basics of school security and safety; and 
- essential steps to ensuring school safety and security.

\section{Literature Review}

This section explores the nature of the school environment safety and security and the basics of school safety and security.

\subsection{The nature of the school environment safety and security}

The school environment can be understood as the sum total of all features of a school that create the learning environment or effective learning spaces. Clearly this refers to both the internal and external spaces of school environments. Kuuskorpi and González (2011) define the school environment in its widest sense, as "a combination of formal and informal education systems where learning takes place both inside and outside of schools"( p. 2). Indeed, a school environment comprises both the physical and psychosocial spaces and provides a context and a link among activities at the school in such a way that they all are aimed at, not only safety and security, but effective and productive education and achievement of schooling goals. The school environment should thus be understood as spaces occupied by school communities in executing effective teaching and learning. Thus safe and secure school environments relate to safe and secure physical and psychosocial environments.

The school's physical environment encompasses school buildings and the surrounding grounds and includes physical conditions such as noise, temperature and lighting as well as the physical and biological agents (Henderson and Rowe, 1998, p. 97). The school's physical environment can thus be surmised as comprising the school building and all its contents including the physical structures and infrastructure, the site on which the school is located and the surrounding environment (Wargo, 2004, p. 1). These features can be classified into the school buildings, grounds as well as service systems and procedures aimed at enhancing safety and security.

School buildings include inter alia, classrooms, stairwells and passages, offices, libraries, laboratories, tuck-shops, toilets/closets, and storerooms (Wargo, 2004; Garret, 2005). Other aspects of the physical environment include materials used in floors, walls and ceilings, signage, safety provisions and access for disabled persons. School grounds or campus are generally categorised into the surroundings, which include the perimeter fencing and ingress and egress points like gates, walkways, paths and sidewalks, playgrounds, vehicular routes and parking areas, landscaping and signage. In essence, the school surroundings constitute all school areas that are attached to the school environment. This includes the area immediately surrounding the school as well as all school campus areas that are not occupied by buildings. Therefore school grounds provide the basis for safety and security of the school interior - including buildings and areas occupied during contact and non-contact time. Service systems and procedures include, inter alia, systems for drainage and sanitation, waste disposal and management, electricity, alarm, fire, communications, emergencies and evacuations procedures, visitation procedures, vehicular drop-off and pick-up points, procedures for leaving the school campus during teaching and learning hours, access control, parking and vehicle control, mail, packages and delivery systems and intrusion detection. Therefore service systems and procedures relate to best practices in safety and security as manifested in deliberate human actions and behaviour.

The school's psychosocial environment expresses the school's climate and encompasses the attitudes, feelings, values and behaviours of learners and staff and is reflected in the physical and psychological safety, positive interpersonal relationships, recognition of individuals' needs and successes, support for and building of self-esteem in learners and staff and support for learning (Henderson and Rowe, 1998, p. 97). In this sense, the school's psychosocial environment gives expression to the way in which learners and staff respectively experience the quality of educational and of working life at the school. To that end, a safe and secure psychosocial environment is one that is free from negative behaviours such as discrimination, bullying, violence, all forms of harassment and punishment and instead, enhances self-esteem, fosters co-operative, caring and respectful behaviours, promotes respect for individual differences and cultural traditions and fosters relationships and communication among the school management, staff and learners (Voices \& Choices, 2003).

Therefore the safety and security of the school environment entails ensuring that the school's physical spaces provide usable, well-maintained and safe facilities, which most importantly, prevent injuries and provide safety and security as well as limit the occurrence of unbecoming behaviours that negatively impact the psychosocial school spaces. In this regard, I argue that the safety of the physical environment is a foundation to the safety of the psychosocial environment in that when safe and secure, it provides teaching and learning spaces that unlock the potential for processes that make provision for a friendly, rewarding and supportive atmosphere - an atmosphere that supports 
cooperation and active learning, forbids physical punishment and violence, is intolerant of bullying and harassment, values the development of creative activities, connects school and home life, promote equal opportunities and participation, identifies and enhances positive characteristics in the school environment (Kennedy, 2004, p. 61; May, 2003, p. 5; Skevington, 2003, Annexure 3; Calabrese, 2000, p. 83; Henderson and Howe, 1998, p. 100).

\subsection{The basics of school safety and security}

Though safety and security are terms mostly used together to convey the same meaning, it is possible to understand them separately. Doing so helps in understanding the essential steps to ensuring school safety and security as a holistic process.

One the one hand, safety can be understood as a situation or condition that is not dangerous and or that is devoid of threats. In the context of the existence of people or occupants in an environment, safety can be understood as a feeling, experience or perceptions that emanate from the condition or environment that is not dangerous - that is safe. Security, on the other hand and in simple terms, can be understood as a condition that is effected, created or made to exist because certain actions have been taken or certain measures have been put in place. Independent Development Trust (1999) accordingly defines security as referring to "the measures that we take to make the school environment free of crime and violence (and) ... is done by making arrangements within the school, and coordinating people's efforts in such a way as to lower the risk of violence and injury" (p. 3). Such measures can be tangible in that they involve installation or erection of equipment or devices and acting on deficient facilities that pose danger or provide a potential for threats to an environment and its occupants' well-being; or intangible in that they are measures that serve to discourage or repel situations or actions that threaten safety and instead, enhance feelings of well-being and safety. It can thus be asserted that security is a necessary precursor to and a basis for safety.

A safe school environment is therefore, one that is not dangerous and that poses no threats to the school occupants in terms of their physical, emotional and psychological well-being. Because the school is a social system (Theron, 2013, p. 100), a safe school environment can be considered as being free from physical and psychosocial threats and therefore, a secure environment. School safety can then be regarded as a phenomenon relating to the physical and psychosocial environments that are not dangerous and that do not pose any threats to the well-being of the school's occupants. In other words, the school environment has to be secure for safety to be felt or experienced. In the context of the school environment, certain measures have to be put in place to secure it or for security to prevail. Only when the school environment is secure or perceived as being secure, will the school environment be considered safe.

The safety of a school is clearly a condition that encompasses practices that aim at ensuring that the school is secure, both in tangible and intangible ways as well in ways that create feelings and experiences of being safe from the point of view of the school community. To this end, securing the school environment and creating safe conditions involves in the main, two main basic safety and security functions namely, facilities maintenance and surveillance of the school environment.

\subsubsection{Facilities maintenance}

The maintenance of school facilities is crucial for making the school physical environment safe, mainly to prevent injuries and securing equipment aimed at securing the school. While aimed at the repair and upkeep of school facilities, Szuba and Young $(2003$, p. 43) make the point that maintenance is basically concerned with ensuring safe conditions for facility users, be they learners, educators, staff, parents or guests. Accordingly, Organization of American States General Secretariat (1998, p. 1) describes school maintenance as an organisational activity carried out by the school community in order to prolong the life expectancy of school buildings, its furniture and equipment. Facilities maintenance also includes the maintenance of service systems and procedures. The maintenance of service systems and equipment involves formulation of policies that clarify the standards necessary to design, construct, equip, maintain and operate the physical environment; financing these systems; and ensuring that policies are implemented (California Department of Education's School Safety and Violence Prevention Office, n.d.). For example, service systems like sanitation, electrical, fire, security including security equipment need to receive consistent and effective maintenance for their continued efficiency. This includes procedures for operating machines and equipment that need to be updated and upgraded. Facilities maintenance comes in the form of various types such as:

- Emergency maintenance, which is concerned with the repair or replacement of facility components or equipment requiring immediate attention because the functioning of a critical system is impaired or because health, safety, or security of life is endangered and may become necessary with little or no advance 
scheduling when there is a failure of a significant component that either makes the system unusable, or carries significant risk for continued system usability and, at times, a component that may increase the likelihood of a more widespread failure (AITS, 2004; UCSC Physical Plant, 2004). Emergency maintenance requires that there be constant vigilance of school facilities and that these should be inspected regularly for any signs of defects. It is also imperative that schools should have plans for dealing with emergency maintenance. For instance, in the school's maintenance budget, there should be an allowance for any emergencies that may occur. The school's incident register and the monitoring of previous emergency maintenance needs would provide a critical indicator for future unexpected emergencies and these can range from damaged buildings and equipment to safety systems and procedures.

- Routine maintenance, which is the repair, replacement and general upkeep of the grounds and buildings (Carter and Carter, 2001). Furthermore, these authors emphasize the fact that routine maintenance allows for the continued use of a space for its intended purpose and serves as an additional manifestation of ownership and caring. An example could be the maintenance of electric systems in order to avoid unintended injuries that may result from electrocution as well as prevent the malfunctioning of crucial equipment like alarm and communication systems at critical moments. Routine maintenance also lays the ground for effective predictive maintenance.

- Preventive maintenance, which is the scheduled maintenance of equipment, such as the replacement of air conditioner filters every ten weeks or the semi-annual inspection of water fountains (Szuba and Young, 2003, p. 74). Preventive maintenance is crucial in so far as it ensures that equipment is always in good working order and provides safety. An example could be the maintenance of electric systems so as so avoid and pre-empt unintended injuries that may result from electrocution. The same could be said for playground equipment where learners spend time expending their energies in a way that is not prescribed, for example, games that could lead to injuries because they are not supervised by adults.

- Predictive maintenance, which is maintenance that forecasts the failure of equipment based on age, user demand and performance measures (Szuba and Young, 2003, p. 74) and is rooted in the proper execution of a facilities audit (Gaither, 2003). This according to Gaither will assist schools to avoid emergencies and dramatically reduce damage. Accordingly, every piece of equipment and related system should be inspected in detail to evaluate its condition and in addition, repair records should be examined to identify recurring problems. Predictive maintenance actually improves chances for surveillance of the school environment and enhances access control measures (Carter and Carter, 2001).

- Corrective maintenance, which addresses the deficiencies that inevitably result from unforeseen events, like vandalism, lightning strikes, hail and flooding but excludes activities that expand the capacity of an asset or upgrade the asset to serve needs greater than or different from those originally intended (Grasmick, Hall, Collins, Maloney and Puddester, 2008, p. 5). Hammond Street Developments (2005, p. 26) argue that corrective maintenance covers the basics of a school maintenance programme. It addresses all the repair needs requested by the school. However, this approach does not call for any checking of services before system failure.

- Deferred maintenance, which basically refers to maintenance, system upgrades, or repairs that are deferred to a future budget cycle or postponed until funding becomes available or maintenance and repair deficiencies that are unfunded at the end of the fiscal year on a planned (Masden, 2006) or unplanned basis and are deferred to a future budget cycle or postponed until funds are available (Arizona State University, 2007, p. 3). BOMA International (n.d.) contends that deferred maintenance occurs when preventive maintenance costs are selectively deferred to a future period of time. This approach has merit when a school facility is non-performing or under-performing - when it no longer serves its expected purpose and when cash preservation is critical as well as when activities are delayed or postponed for reasons such as lack of personnel and changes in priorities and change of use (Baltimore County Public Schools, 2007, p. 92).

Maintenance of school facilities can therefore be regarded as the basic requirement for securing the school environment in that it ensures that all equipment and facilities are usable and safe and thus provide conditions that are, as pointed out above, effected, created or made to exist because certain actions have been taken or certain measures have been put in place, in this case, maintenance systems. Maintenance of school facilities complements surveillance systems by availing working and usable facilities that enhance the surveillance of the school environment. 


\subsubsection{Surveillance}

Surveillance, as the word suggests, implies being constantly on the watch and entails, in the context of school safety, monitoring or watching the whole school environment closely. This means ensuring that all areas of the school are constantly observed and monitored regardless of whether they are occupied or not, used or not. This includes even those areas that are located in remote parts of the school campus and in essence, implies acute awareness of features in the school environment. In considering surveillance, three important basics are significant namely, natural surveillance, access control and territoriality.

\subsubsection{Natural surveillance}

Xaba (2006, p. 568) draws Reid's (2000) definition of surveillance as entailing monitoring the whole-school environment, removing obstacles from the school grounds, (e.g. solid walls, lack of windows, shrubs and trees), ensuring clear visibility of main entrance(s), locating parking areas so that they are visible, keeping unused buildings and doors securely locked, demarcating 'out of bound' areas, eliminating blind spots provided by doorways, fences, buildings and landscaping including access control. Carter and Carter (2001) contend in this regard that the objective of natural surveillance is to provide an environment in which one can see and be seen, to eliminate hiding or hard-to-see places and thereby increase the perception of human presence and increase visibility throughout a building and on campus grounds. Natural surveillance therefore enhances supervision by ensuring that open sight lines exist through the design and placement of buildings, landscaping components, lighting and access control (Kirk and Ward, 1998, p. 6). Other examples of natural surveillance include placement of windows as they relate to doors and people, lighting passages, pavements, entrances and exits. With natural surveillance comes the need for maintenance. Simpers $(2004$, p. 2) argues that if a school does not maintain its natural environmental features, the surveillance efforts will be useless. To demonstrate her fact, Simpers (2004) poses the following questions: What good is a light fixture if the bulb no longer works? What good is shrubbery along the perimeter of a building if it has grown so tall that it creates a perfect hidden pathway for trespassers?

\subsubsection{Access control}

Access control refers to the physical guidance of people coming into and going from a space. Examples include the judicious placement of signage, entrances, exits, fencing, landscaping, lighting and other way-finding elements, such as the use of colour to provide orientation and direction (Carter and Carter (2001), and involves a way for learners, educators and visitors to get from one place to another (Simpers, 2004, p. 2). It also controls who is allowed into certain areas. According to Kennedy (2004, p. 2), access control also means that visitors arriving at the school must report directly to the administration office before doing anything on the school campus. In summary, the objectives of access control are to keep people on safe routes, enhance emergency responses, decrease the sense of being lost, avoid conflicts and prevent trespassing (Carter and Carter, 2001). Kirk and Ward (1998, p. 5) outline access control as relating to the:

- campus perimeter, which seeks to ensure that visitors and guests pass through a particular point or entrance and have a designated protocol of interacting with the school community;

- entrances and exits, which relate to minimising the number of entrances and exits to the school campus and direct traffic flow, both vehicular and pedestrian, to eliminate confusion and congestion and to provide ease of observation. This includes designing parking areas to limit and control access;

- visitor parking, which seeks to identify visitor parking with proper signage and control visitor traffic, in such a way that it can be easily supervised from the main office by assigned personnel; and

- visitor screening, which relates to clearly worded and placed signage so as to direct visitors to the main office or designated visitor reception areas where they can be screened, using uniform visitor screening procedures, to ensure that they have legitimate business on the school campus.

Access control therefore, requires complete and acute vigilance and awareness as critical elements to ensuring a secure school environment. In this regard, both human actions pertaining to environmental awareness and technological equipment for screening are important. 


\subsubsection{Territoriality}

Territoriality entails the use of physical elements to create a sense of ownership among learners and educators. According to Carter and Carter (2001), territoriality means the use of physical attributes that delineate space and express ownership. Simpers $(2004$, p. 2) asserts that landscaping, fencing, artwork, signs and even school uniforms are some examples of how this can be achieved by helping to create a sense of belonging. Defining the purpose of each area on the school grounds also adds to this sense of ownership, which ultimately breeds in a kind of school climate that is conducive for teaching and learning (Simpers, 2004, p. 3).

Carter and Carter (2001) points out that the objectives of territoriality are mainly to increase a sense of pride and ownership felt by learners, educators and other school personnel and put others on alert that they are coming into a territory that is owned and cared for. This gives the message that unacceptable behaviour will not be tolerated.

Taking the three elements of surveillance exposed above, Harrison (2003)) outlines some practical steps to effective security of the school environment namely:

- Providing a substantial secure boundary, limit access points for vehicles and pedestrians and negotiating the removal of public rights of way across the site;

- Using landscaping to enhance security and resolve aesthetic issues;

- Limiting and controlling the main access route for visitors to the school by ensuring that it is direct, easily accessible and clearly signed and ensuring that main access routes do not allow opportunities for informal unsupervised access to other parts of the school;

- Keeping the building shell simple in shape and plan to aid surveillance and reduce hiding places by avoiding recesses or ledges, which might provide opportunities for shelter that could be abused;

- Considering and introducing where possible, natural surveillance from windows across open spaces playgrounds and car parks;

- Ensuring that roofs generally are designed to inhibit casual access and avoid hiding places for intruders and avoiding providing easy climbing facilities to roofs, which may be provided by rainwater down pipes, overflow pipes and low gutters as well as avoiding steps provided by wall features or adjacent railings;

- Securing car parking and ensuring that it is well-lit with limited access points including providing intruder alarm systems linked to police or security response;

- Providing facilities to keep rubbish disposal away from buildings;

- Providing 'designed for purpose' secure areas where high value or vulnerable items of equipment are used; and

- In high risk areas, considering shutters or grills for windows, sprinkler systems, facilities for CCTV and manned guarding.

The preceding exposition of the school environment and safety and what school safety and security entails, projects the need for a holistic approach to school safety and security. Clearly then the essential steps entail having wellgrounded knowledge of school safety and security features and measures; and a thorough understanding of school environment safety and security requirements. In essence this concerns actions that secure schools use to promote safety and engender behaviours that generate safe school environments on a daily basis. This then requires systematic and coordinated activities.

\section{Essential Steps of an Approach to School Safety and Security}

Based on the foregoing exposition of basic features of school safety and security, it can be averred that basic elements of safety and security entail the school's physical environment, security measures and safety and security policies that include procedural behaviour (May, 2003) aimed at responding to safety threats. Therefore essential steps require an approach that recognises each and every aspect of securing and creating school safety through systematic processes that leave no area to chance and seek to address gaps in the implementation of existing school safety and security measures. A holistic approach to school safety and security takes into consideration aspects of the school's physical and psychosocial environments and purports to involve as many essential stakeholder representatives as is possible. I therefore propose a four step approach as follows: 


\subsection{Create or re-establish an organisational structure for safety and security}

This is in the domain of the school governing body's (SGB) role of engaging in a strategy formulation process for school safety and security. A holistic approach is thus a strategic planning process and begins, as a first essential step, by the SGB setting up a School Security and Safety Committee (SSSC) and its office-bearers. The aim of the SSSC is basically that of creating an enabling environment for safety and security, planning and the implementation of safety measures. Being a holistic process also means focusing on the safety and security of the whole school environment and involving all stakeholders, which should include creating partnerships with community structures essential for enhancing school safety and security (Pollack and Sundermann, 2001). In this regard, partnerships would involve learners, educators, parents, law enforcement agencies, civic and business leaders including Non-Governmental Organisations and Community-Based Organisations. The involvement of stakeholders in such partnerships is crucial in that safety threats at schools usually mimic threats in the communities and require collaboration with community entities. The involvement of community structures is also valuable because such involvement creates space for community resources to be deployed and utilised at schools. For example, community-based organisations can assist the school to deal with issues such as gender-based violence, security and discipline, health promotion, human rights, activities that improve the performance and wellbeing of the learners, for example, extramural activities or the provision of feeding schemes and will assist with orphans and other vulnerable children (Department of Education, 2008:37).

\subsection{Determine the current status of safety and security of the school}

This involves a series of actions that depend on the current conditions of the school. Therefore, the initial action should involve a school environmental scanning process, with the intention of determining the current status of the school's physical and psychosocial environment and identifying gaps in security features and safety measures. For this purpose, an active action and planning team or teams that consist of school staff, parents, earners and community members, should be established. It is important that such teams possess the necessary problem identification in order to collect data on the current status of the school's safety and security features and measures. For this purpose, the teams can use tools like checklists, questionnaires, inventories and be able to interview school community stakeholders to collect as comprehensive safety and security data as is possible. In addition, data can be collected using community forums and social indicators like incidence reports, suspension or expulsions for violent behaviour, substance abuse statistics and weapon possession (Pollack and Sundermann, 2001). This should be done against existing legislation concerning school safety and security and best practices in school safety as highlighted on matters relating to knowledge on basic safety and security, basically the three elements of school safety and security highlighted elsewhere in this text namely, facilities maintenance, surveillance and access control.

School environmental scanning will culminate into a well-informed school profile, which will basically inform the school's basic safety and security status by pointing out enabling and disabling factors regarding safety and security, thus providing a database for taking prudent decisions and effecting improvements where necessary in terms of priorities. Therefore this step addresses the acquisition of pertinent information on the essence of school safety and security.

\subsection{Engage in school safety and security planning and develop an extensive school safety and security action plan}

This step involves actual action planning for school safety and security, which basically begins actions aimed at securing the school, promote safety and engender behaviours that enhance and promote a safe school environment. The action plan involves setting objectives for improvement and prioritising areas that need to be addressed as a matter of urgency and in the immediate-short-term and those that need to be addressed in the long-term. Past incidences and reports of current trends in safety-threats are of paramount importance for prioritisation at this stage. A crucial consideration at this planning stage, is that of setting achievable and measurable goals so as to ensure that implementation takes place and is monitored constantly. The best way of conducting action-planning is by including all stakeholders identified above and ensuring that inputs are solicited from as wide a range of school stakeholders as possible, especially members of the immediate school community, whose buy-in and ownership of "new" safety and security measures is critical. This can include planning for apposite knowledge acquisition from internal sources and external agencies as highlighted earlier.

\subsection{Implement, monitor and evaluate}

An important and fourth essential step is the involvement of the school community and in essence, soliciting their buy-in 
for the implementation of the action plan devised as pointed out above. This is an important step in that it will determine the success and effectiveness of the implementation process of safety and security measures decided upon. This is in fact, mainly because safety and security measures will most definitely require a change of behaviours and attitudes and will impact on how people have been doing things and create a destabilisation of their comfort zones. This step essentially involves publicising and advocating for school safety and security and introducing measures with an emphasis on implementation.

Once the school community's buy-in has been secured, the next essential step is the actual implementation, monitoring and evaluation of safety and security measures that have been put in place. This is the most critical step as it entails "doing". Included in this, must be securing the school environment by whichever means that will have been decided upon. Throughout this process, there will be a need for communication across the school community, but most importantly, between the SSSC, the school management and the SGB. This is because at this stage, activities might include training in certain aspects of security and installation of security features. This requires constant monitoring and evaluation of the effectiveness of measures put in place. It is also important to note that while the comprehensive approach will have one comprehensive plan, there will be smaller more direct plans that address specific issues and areas of safety and security. For this reason, constant monitoring and evaluation is crucial to ensure that a holistic implementation drive is achieved and that there is vigorous monitoring and evaluation of the effectiveness of the implementation processes. Therefore incident notation or recording and constant feedback are essential so as to keep track of the need to reinforce and or re-plan for improvement where necessary. This step, which includes for its effectiveness and success, monitoring and evaluation should be done meticulously and conscientiously through follow-up research and observations to determine whether safety measures implemented are having the desired impact.

\section{Conclusion}

It is clear that securing a school and making it safe requires a holistic approach that does not only address adverse behavioural tendencies like violence and bullying, but addresses the basic features of the school environment that promote the implementation of measures aimed at curbing such tendencies. Therefore creating a safe and secure school requires addressing the whole school environment comprising the physical and psychosocial environments. It can also be deduced that addressing the physical environment of the school lays the ground for dealing with various psychosocial threats that commonly occur at schools. It is therefore important to adopt a balanced view of the school security and safety in so far as both the physical and psychosocial school spaces are concerned. Emphasis in dealing with safe and secure school planning should always be on the implementation of safety and security measures; hence the need for a stakeholder holistic approach and the need for a constant monitoring and evaluation feedback loop that forms a continuous process of enhancement, improvement and or re-planning.

\section{References}

AlTS. (2004). System and emergency maintenance. http://www.aits.uillinois.edu/live/Site.xml?document=ArtSystemEmergency Maintenance.xml\&focus=null (Accessed March 12, 2006).

Arizona State University. (2007). Deferred maintenance overview. ASU facilities management and capital programs. http://www.asu.edu/vppa/statelocal/files/Deferred_Maintenance_Overview.pdf (Accessed June, 17 2009).

Baltimore County Public Schools. (2007). Comprehensive maintenance plan. Baltimore: Office of Strategic Planning.

BOMA International. (n.d.). Minimize your assets with a preventive maintenance Plan. http://www.enterprisehvac.com/co_info/ pdfs/PMPlan.pdf (Accessed 17 June 2011).

Burton P., \& Leoschut L. (2013). School violence in South Africa: Results of the 2012 National School Violence Study. Cape Town: Centre for Justice and Crime Prevention, Monograph Series, No 12. March.

Calabrese, R.L. (2000). Leadership for safe schools: A community-based approach. London: Scarecrow Press, Inc.

California Department of Education's School Safety and Violence Prevention Office. (n.d.). Safe school plans. Sacramento: Office of the California Attorney General, Crime Prevention Centre.

Carter, S.P. \& Carter S.L. (2001). Planning safe schools. American School \& University. 73(12). http://asumag.com/print/cpted-crimeprevention-through-environmental-design/planning-safer-schools. (Accessed 17 June 2013).

City Press. (2014). 8-year-old dies after being beaten and kicked by bullies. 25 Feb. 2014. http://www.citypress.co.za/news/8-year-olddies-beaten-kicked-bullies/. (Accessed 17 March 2014).

Department of Education. (2008). Implementation guidelines: Safe and caring child-friendly schools in South Africa. Pretoria: Government Printers.

Gaither, J.F. (2003). The perfect patch. American School \& University. Dec. http://asumag.com/mag/university_perfect_patch/ (Accessed 14 April 2013). 
Garret, S. (2005). Safe schools guide: Selected strategies and resources. A safe school through prevention. Oklahoma City: Oklahoma State Department of Education.

Harrison, D. (2003). How to secure your school. Building Specifier November. http://www.bdonline.co.uk/how-to-secure-your-school\%E2\%80\%A6/1032009.article (Accessed 17 June 2009).

Grasmick, S, Hall, R.E., Collins, A.C., Maloney, T. \& Puddester, F. (2008). Guidelines for maintenance of public schools facilities in Maryland. Maryland: Interagency Committee on School Construction.

Hammond Street Developments. (2005). Supporting maintenance planning through audits. The why and how of predictive maintenance planning. http://www.hsd.com.au. (Accessed 14 December 2010).

Henderson, A. \& Rowe, D.E. (1998). A healthy school environment. In E. Marx, F. Wooley, \& D. Northop (Eds), Health is academic. A guide to coordinated school health programs pp. 96-115. New York: Teachers College Press.

IPT (Independent Project Trust). (1999). Protecting your school from violence and crime. Guidelines for principals and school governing bodies. Durban: IPT.

May A (2003) Changing face of school security. Building Operating Management. Nov. http://www.facilitiesnet.com/bom/article. asp?id=1636 (Accessed 23 April 2014).

Kennedy, M. (2004). Providing safe schools. American School \& University. 76(5), 61-64. Jan. http://asumag.com/mag /university providing safe schools/. (Accessed 14 May 2013).

Kirk, P.J. \& Ward, M.E. (1998). Safe schools facilities planner. Raleigh, NC.: State Board of Education, Department of Public Instruction.

Kuuskorpi, M. \& González, N. (2011). The future of the physical learning environment: school facilities that support the user. Organisation for Economic Co-Operation and Development (OECD), 2011/11.

Maphalala, M.C. \& Mabunda, P.L. (2014). Gangsterism: Internal and external factors associated with school violence in selected Western Cape high schools. Journal of Sociology Social Anthropology, 5(1), 61-70.

Masden, J.J. (2006). Paying for deferred maintenance. Buildings magazine. http://www.buildings.com/article-details/articleid /3161/title/paying-for-deferred-maintenance.aspx (Accessed 14 May 2012).

Mncube, V. \& Harber, C. (2013). The dynamics of violence in South African schools: Report. Pretoria: UNISA. http://www.unisa.ac.za /contents/colleges/col_education/docs/The\%20Dynamics\%20of\%20Violence\%20in\%20South\%20African\%20schools.pdf. (Accessed 17 March 2014).

Mncube, V. \& Madikizela-Madiya, N. (2014). Gangsterism as a cause of violence in South African schools: The Case of six provinces. Journal of Sociology and Social Anthropology, 5(1), 43-50.

Moloto, M. (2014). Boy dies after falling into pit toilet. January 222014 at 09:26 am. The Star. http://www.iol.co.za/news/southafrica/limpopo/boy-dies-after-falling-into-pit-toilet-1.1634909 (Accessed 14 May 2014).

Naik, S. (2014). 'Progress' made in school deaths probe. Saturday Star, 15 March.

Nhlapo, V.A. (2006). Managing school safety in the primary school. Vanderbij|park: North-West University. Unpublished M.Ed disseratation. p. 171.

Organization of American States General Secretariat. (1998). Maintenance manual for school buildings in the Caribbean. USAID-OAS Caribbean Disaster Mitigation Project: Unit for sustainable development and environment. http://www.oas.org/CDMP/document/ schools/maintman.htm. (Accessed 08 May 2010).

Pollack, I. \& Sundermann, C. (2001). Creating safe schools: A comprehensive approach. Juvenile Justice - School Violence, VIII(1). June.

Simpers, B. (2004). Safety first. American School \& University. 76(6), 12-14, Feb. http://asumag.com/mag/university_safety_first/ (Accessed 23 April 2014).

Skevington, S. (2003). Creating an environment for emotional and social well-being. Geneva: World Health Organization's information series on school health. Document 10.

Szuba, T. \& Young, R. (2003). Planning guide for maintaining school facilities. Washington DC: National Forum on Education Statistics.

The Citizen, (2014a). Pupil caught assaulting teacher on camera (VIDEO). 17 March.

The Citizen. (2014b). Free State pupil shoots teacher. http://citizen.co.za/50517/free-state-pupil-shoots-teacher/. (Accessed 17 March 2014).

UCSC. (2004). Frequently asked questions. University of Carlifornia. http://ucscplant.ucsc.edu/ucscplant/index.jsp?page=FAQ\#faq11 (Date accessed 12 March 2008).

Van Jaarsveld, L. (2011). An investigation of safety and security measures at secondary schools in Tshwane, South Africa. Pretoria: UNISA. Unpublished M.Tech. dissertation. pp. 193.

Voices \& Choices. (2003). Introductory document. http://www.phac_aspc.gc.ca/vc_ss/intro_e.html. (Accessed: 13 January 2006).

Wargo, J. (2004). The World Health Organization's information series on school health: The physical school environment. New Haven Connecticut: Yale University.

Xaba, M. (2006) An investigation into the basic safety and security status of schools' physical environments. South African Journal of Education, 26(4), 565-580. 